\title{
The Aesthetic Choice and Style Tendency of Light Crimson Colored Porcelain Landscape Paintings
}

\author{
Guoxin Hao \\ Department of Painting \\ School of Fine Arts \\ Tsinghua University \\ Beijing, China
}

\begin{abstract}
In the end of the Qing Dynasty, the light crimson colored porcelain began to emerge. Some of the literati painters began to create porcelain paintings. In the specific historical circumstances, light crimson colored porcelain landscape painting established its aesthetic tendency according to these two reference objects of business purpose and the spirit of traditional literati. It inherited the elegant, wild aesthetic characteristics of the literati painting and desalination bleak, solitary cold and other worldliness artistic ideal, porcelain painting often show a fresh and gratifying secular touch. The successors of the light crimson painting have always maintained a relatively consistent aesthetic direction and process methods, which make the overall style of its porcelain art creation have the same strain, and sprouting out six styles tendencies. The emergence and development of light crimson painting are "literati Painting on porcelain", is also a creation move of the porcelain painting use its colorful method to interpret some part of aesthetic pursuit and artistic spirit of literati paintings, so it has an important reference value with Chinese painting. This creation is based on the specific aesthetic consensus restrictions. It has great significance meaning for today's porcelain parting to emphasize artistic style and relative stability of craft while emphasizing the diversity of artistic forms.
\end{abstract}

Keywords-light crimson painting; literati painting; landscape painting; porcelain painting style; stability

\section{INTRODUCTION}

In the 1860 s and 1970 s, the literati painters represented by Chengmen began to participate in the process of porcelain painting, which promoted the development of the Light crimson colored porcelain ${ }^{1}$ into a new period, and created the first of the literati painter consciously participate in the porcelain creation. The light crimson painters not only need to face the changes in painting techniques brought by different

\footnotetext{
(1) Light crimson is a color painting technique in Chinese landscape painting, its color effect is simple and elegant. Crimson, refers to dark red, in pigment it refers to ocher stone color. On basis of ink landscape to render rocks and trees with ocher-based color, the color is simple and elegant which contrast the ink very well. Most of Yuan Dynasty painter Huang Gongwang, Wang Meng's landscape paintings use this performance technique. (Reference: Wang Qingsheng editor. Literary and creative knowledge dictionary. Wuhan: Yangtze River Literature and Art Publishing Company .1987. P534.) Light crimson colored porcelain is famous by borrowing light crimson landscape painting's painting style, technique and aesthetic pursuit during porcelain painting.
}

painting materials, but also need to build the balance between inherit the spirit of traditional literati painting and the acceptance of painted porcelain goods. Therefore, the light crimson artist made some aesthetic pursuit selection among the literati paintings with rich content and integrated the fashion of the times to form an aesthetic orientation which is widely recognized in the literary, official and business circles.

\section{The AESTHETIC CHOICE OF LIGHT CRIMSON LANDSCAPE PAINTING}

The origin and development of light crimson colored porcelain depends on the society's specific historical environment and opportunity ${ }^{(2)}$, for the aesthetic choice, is due to the development of commodity economy ${ }^{3}$, the emergence of modern civil strata promoted the late Qing culture develop to the secularization direction ${ }^{(4)}$. People pay more attention to real life and human secular sentiment. This is the external cultural environment for light crimson to exist as a crafts category, and the one which directly influence it is scholars, merchants and officer's aesthetic cognition and consensus. Especially it is worthwhile to note is "Jia Ming Er Ru Xing" the influence of Huizhou merchants, they always attach importance to the "authentic" thinking of traditional landscape painting, they like poetry, calligraphy and painting together in

\footnotetext{
(2) The potential cause of the artistic style of light crimson colored porcelain is the increasing influence of the Yuan-Ming-Qing painting art on porcelain painting. The porcelain painting has gradually become the decoration and appreciation object. The important influence of Huizhou merchants and the destruction of the Jingdezhen royal kilns factory made by the Taiping Heavenly Kingdom are the direct cause of a number of painter with high poetry painting and calligraphy quality become professional porcelain painting artist or participate in porcelain painting. (See Liu Changbin's thesis "The art style of light crimson colored porcelain painting").

${ }^{(3)}$ The development of commodity economy at the end of Qing Dynasty, the painting purpose of the famous light crimson artists and painters is to create cultural products which have been generally pursuit by a particular group of people rather than the Tidao" "Dim" "Alone" feelings that the past literati pursuit. Even the literati painter like Cheng men, his painting must also be to make a living as the prerequisite, which to some extent, restrained the aesthetic characteristics of their painting to pursue "self entertainment". The characteristics of literati paintings are various, so they choose the vivacious, elegant and wild these relatively neutral aesthetic tendencies, and these aesthetic influence factors finally embodied in Cheng men's establishment and selection of the aesthetic tendencies for light crimson painting.

(4) Li Zehou's view in "The course of Aesthetics" is the characteristic of Ming and Qing culture is "human secular".
} 
one, but they also sense the "authentic" landscape painting was gradually lost its original charm, so there are requirements to pursue the unconventional atmosphere.

At the end of Qing Dynasty in the field of landscape painting, the "authentic" painting started from the beginning of Qing Dynasty advocated by four Wang and the landscape painting which the four monks attach importance to "write creation" form a contrast, in fact in the literati appeared two aesthetic tendencies coexist situation. At this time the new trend of singularity which represented by "Yangzhou Eight Strange" also has a wide range of effects, which makes the new emerging light crimson porcelain landscape paintings show a variety of aesthetic orientation integration feature. On one hand, the main painters of light crimson painting all worked in the royal kiln factory, the "authentic" thought of literati landscape painting still has certain influence, and the thought of "learn from the ancient" is consistent with the aesthetic preference which Hui merchants and the court always held, so light crimson always stick to first study traditional literati painting master's brushwork, schema and then start the art creation. On the other hand, the style of "like new and strange" idea and "rewriting creation" idea make the light crimson take emphasis on the stimulation of visual forms and the artistic expression of color.

Cheng Men ${ }^{(5)}$, Jin Pinqing and Wang Shaowei as "The Three Masters of Light Crimson Painting" accept the above factors' influence and contributed to the overall style characteristics of light crimson colored porcelain, which are: the color is gray, light and elegant, simple and easy, moist and fresh, use pen to express the emotions and feelings. It finally influences the creation and development of the entire light crimson colored porcelain landscape painting category.

In the beginning period of light crimson painting, the aesthetic taste embodied in Cheng men's porcelain painting works has a great influence. He was recognized as the leader of light crimson porcelain painting, his aesthetic pursuit of art came from the aesthetic thought of traditional literati paintings, but he made a careful selection. His works pursuit wild life fun not flaunt "Jueshi Daoxuan", pursuit elegant without "lonely and indignant", pursuit individuality without "proudly unyielding", pursuit comfort without bitterness, pursuit quiet without tragic. His paintings also often show a light, gratifying secular sentiment. This is the emotional expression given by the secularization of the end Qing culture. The prominent example is his aesthetic pursuit transformation of Xin'an painting school. Although he is a representative of Xin'an School of painting, he chose the aesthetic features of his school of painting in porcelain painting, he made a dilution and reduction of the indelible indomitable classic aesthetic pursuit of Xin'an painting school, instead of the artistic orientation which pursuit to rhythm, fresh, can travel also can settle down. Although he has been upholding the art method of learn from ancient, he learn from Mi's Clouds and Mountains style, Wang Hui ,Zha Shibiao, Tie Sheng, but he advocated in explore new ideas in the limitation, artistic creation is still an important goal. When he talked about learn from ancient and make creation, he said: "Where the painting regardless of learn from ancients, as long as he can get the taste of painting it is cheerful." In his porcelain painting he was a typical literati painter who focuses on color and considers less on ink, this is not because it is difficult to express ink effect on porcelain, but because of the creation purpose. Although he had carefully created pure ink (black material ${ }^{(6)}$ ) on porcelain: ("Wufeng Huancuitu porcelain plate" "Fig. 1"), ink skill is extremely high, but he just slightly tasted and did not continue this style. On the contrary, he has a great interest to interpret Mi's Clouds and Mountains style with color ("Fig. 2"), so he had many works about it, such as the mountain processing method in "The Fifth plate of Xiaoxiang Eight Sights"("Fig. 3"), "Changjiang fishing porcelain plate", "Zhuli Lutun Tu porcelain Plate" and other works is colorful and full of changes. And he said, "when paint Yunshan it should focus on the quality, no need to copy Mi's", from this we can see that "imitation of Mi's Clouds and Mountains Style" is actually a kind of elegant rhetoric, but in reality he use color to "change Mi’s Clouds and Mountains style".

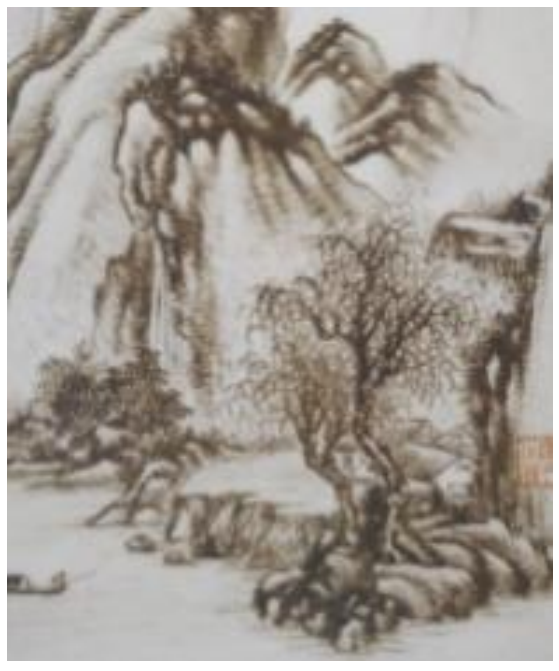

Fig. 1. Partial painting of "Wufeng Huancui Porcelain Plate", painted by Cheng Men

"Wufeng Huancui Porcelain Plate" was drawn in the 2nd Guangxu years (1876), $39 \mathrm{~cm}$ long, $26 \mathrm{~cm}$ wide "Fig. 1". Inscription: Wufeng Huancui Daomenqian (Five mountains circle the green environment to the front door), Pibu Changliu Bujinian (the waterfall always flowing down so not remember time). Chunliu Bancun Renzile (Spring willow make the village people very happy), Xianlai Shishang Diaoyuchuan (when they are free they often go fishing). Bingzi Qiuyueshanghuan (Bingzi year autumn), Chengmen Xueli Xie (Chengmen wrote). Stamp: Kuan Cheng. Side stamp: Fu Shi Zhen Cang. Old collection of Mr. Xiong Zhongfu of Jingdezhen, Jiangxi Province.

\footnotetext{
${ }^{(6)}$ Black material is made of cobalt ore mixed with lead powder.
}

(5) Cheng Men, born in 1833, died in 1908. He was from Qianxian, Anhui, also known as Zeng Pei, style name is Song Sheng, courtesy name is Xue Li, Li Daoren. 


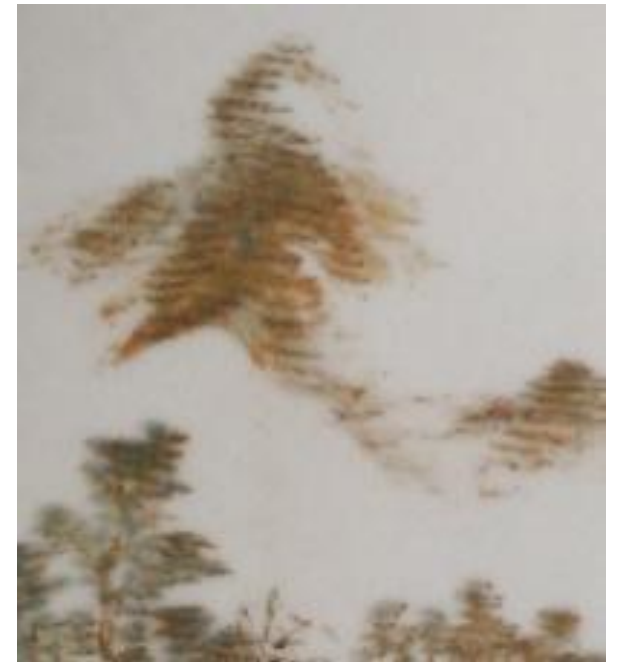

Fig. 2. Partial painting of "The Fifth Plate o Xiaoxiang Eight Sights".

"Fig. 2", the 3rd Guangxu year (1877), $39 \mathrm{~cm}$ wide and 26 $\mathrm{cm}$ high, Old collection of Mr. Xiong Zhongfu of Jingdezhen, Jiangxi Province.

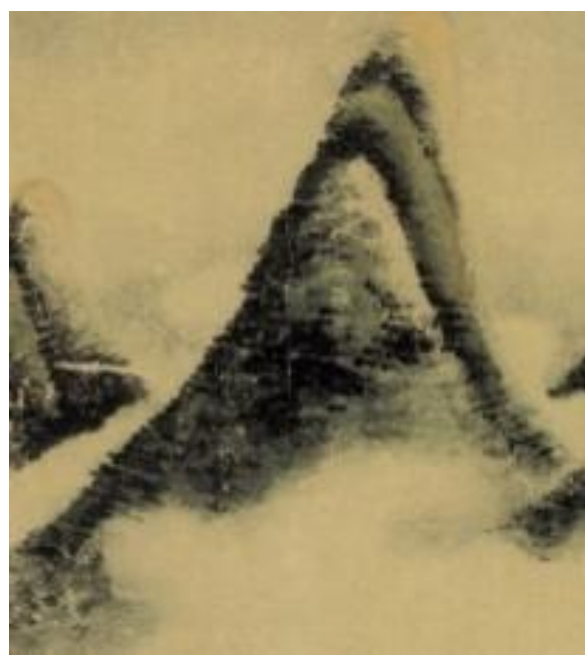

Fig. 3. Partial painting of "Chunshan Ruisong Tu", Scroll painting by Mi Fu from Song Dynasty, paper ink, color, vertical: $35 \mathrm{~cm}$, horizontal: $44 \mathrm{~cm}$.

Mi Fu did not left a confirmed work, this "Chunshan Ruisong Tu" may be imitated by the Song people "Fig. 3." But speculated that the style should be Mi's Clouds and Mountains style. Collection of National Palace Museum in Taipei.

The aesthetic pursuit established by Cheng Men in the porcelain painting has the universality of the literati class, which is the result of the neutralization of the literati painting art. This us decided by Cheng men who as a literati individual and commercial producers this dual identity. Although he as a literati professional painter, but this can not change the commercial nature of his painted porcelain, moreover it cannot change the commercial nature of the entire light crimson porcelain industry. Painted porcelain must take make a living as its prerequisite, which also to a certain extent, inhibited the extreme personalized art exploration. And it encourages the form creations with fashion sense and consensus aesthetic tendency. As the success of this aspect, Cheng men also received the recognition of future generations, his artistic tendency was chased and followed up to 60 years. The tradition of literati painting into porcelain has been formed since then. Later it affected the art pursuit of "Zhu Shan Bayou". Hand-painted porcelain level also has been a general improvement.

\section{The STYLE TENDENCY OF PORCELAIN LANDSCAPE PAINTING}

Due to the simplification of the process, Cheng Men, Jin Pinqing and Wang Shaowei's art development and light crimson colored porcelain craft were deeply influenced by the merchants (mainly Huizhou merchants), some officials and literati class's tastes, so attracted a large number of painters, literati and officers involved in porcelain painting creation. They communicate and influence with each other, together with personal accomplishment, class and purpose differences, the overall style of light crimson porcelain painting appeared an imbalance in specific works, and then evolved into a variety of style tendencies.

\section{A. Simple Writing to Express Nature-Tend to Freehand Lyrical Expressions}

Southern and Northern Dynasties Zong Bing was the first person to introduce Gu Kaizhi's "Yixing Xieshen" (express emotions with shapes) ${ }^{(7)}$ into landscape painting. In the Ming Dynasty, Tang Zhiqi emphasized the writing interests in landscape. In the Qing Dynasty, Shi Tao and Zhu Da advocated "wrote their own temperament" and wrote "miserable, grief and indignation" emotions. In many porcelain paintings, the porcelain painter expresses the expression of the temperament, bringing intuitive artistic feelings, but this feeling is not the relative personal expression which Shi Tao and Zhu Da pursue, it is not emotion expressions of porcelain painter themselves, but tend to "personality" ${ }^{8}$ show which have been perceived already, so the painting often use the exaggeration of the ancient's "nature writing brushwork". Painting often shows the straight, simple, thick and rough brushwork, the color is simple and the modeling is between "like and not like". Such like in Wang Zhang's "Tea Can with Ladies and Landscape" ("Fig. 4") painting, brushwork is simple and easy, although the shape of objects likes Mi's Landscape works but more laissez-faire. This kind of porcelain painting style tendency is actually inherited the aesthetic pursuit of literati painting to write spirit. Painting strokes often "slip with smooth", echoes the direction, and formed the powerful sense of rhythm with overall smooth quality.

\footnotetext{
(7) "Yixing Xieshen" is first mentioned by Gu Kaizhi in the Figure painting, later Zong Bing, Wang Wei introduce it into landscape painting filed, see "Hua Shan Shui Xu", "Xu Hua".

${ }^{8}$ Actually it is his "personality" not the porcelain painter's personality.
} 


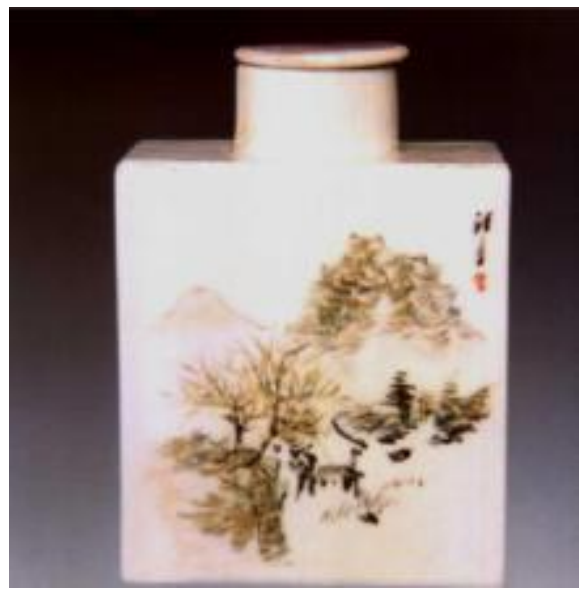

Fig. 4. "Tea Can with Ladies and Landscape" Wang Zhang, the 11th Guangxu year (1885), Han Yun made in winter, Stamp: Yun

\section{B. Gray Color with Strong Emotion-Freecolor Creation}

Completely express literati emotions with color is light crimson's another creation besides green landscape. ${ }^{(9)}$ Unlike the green landscape painting, there is no stylized color setting in light crimson porcelain. The painter can change the color matching freely and subjectively, the mature painter can often get the harmony between the colors during the change, which is very close to the western color relation "tone" change but more subjective and free, the prominent example is a number of artists' imitation and change on the Mi's cloud and mountains works ${ }^{10}$. In the 6 works such as "The Fifth Plate of Xiaoxiang Eight Sights" ("Fig. 2"), "Changjiang Fishing Porcelain Plate" ("Fig. 5"), "Zhuli Lutun Tu Porcelain Plate" ("Fig. 6"), "Light Crimson Colored Drum-Shaped Ewer with Flower and Bird Landscape" ("Fig. 7"), "Square Bottle with Flower and Bird Landscape" ("Fig. 8"), "Shuying Souliangtu Porcelain Plate" ("Fig. 9"), all the mountains are changed from Mi's Landscape works, but because there is no stylized color regulation, painters all painted "Mi's Landscape" with different colors based on their own feelings, but they meet the aesthetic and become a new form. In the "Light Crimson Colored Landscape Square Pot With Phoenix-Headed Spout" ("Fig. 10"), we can see another feature of light crimson painting color. Normally the colors that light crimson painting often use are not so many, but the color brightness is generally high, multi-color makes the picture look gray and elegant. The warm-toned contrast of "Phoenix headed spout pot" makes people feel the joy, this emotion expression has the secular touch which close to people, and is very different to the literati painting's alone and cold mood. There are also many works with extremely rich colors, sometimes there are four or five colors in one mountain, but in the painting is light and

\footnotetext{
${ }^{(9)}$ In traditional painting, the green landscape is regarded as the north school landscape, but he is still the carrier to convey the literati's emotions, such as Ni Zan was once painted green landscape.

(10) As the light crimson color pay attention to conduct creation with the help of ancient writing features, and Mi's landscape has a lofty status, so a lot of porcelain artists imitate Mi's Cloud and Mountains porcelain painting was handed down. Because the light crimson has broad requirements with color covering, so it formed a variety of Mi's Cloud and Mountains color expressions, each one has unique taste and was surprised.
}

harmonious, such as Cheng men's "Cangcui Maoshetu Porcelain Plate". It should be noted that these color collocations are subjective, and its law is not exactly the same with the Western color composition we learned, but also different from folk art color characteristics that we commonly use, so it is worthy of further induced and summarized.

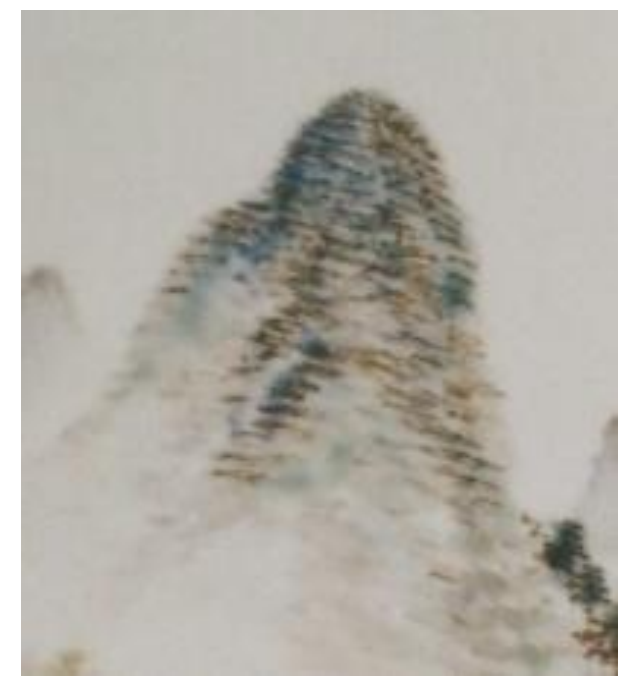

Fig. 5. The partial painted porcelain of "Changjiang Fishing Porcelain Plate" from Cheng Men, the 3rd Guangxu year (1877), $39 \mathrm{~cm}$ wide, $25.5 \mathrm{~cm}$ high. Inscription: Xiaolai Yuqiduo, Bianran Hushanjing. Duyou Buyuren, Qingzhou Shichuru.(In the night the rain and wet air spread all over the lake and mountain road. Only fish-man drove a boat in and out.) ,Spring copy in 1877, wrote by Cheng Men at Xinan. Stamp: Cheng.

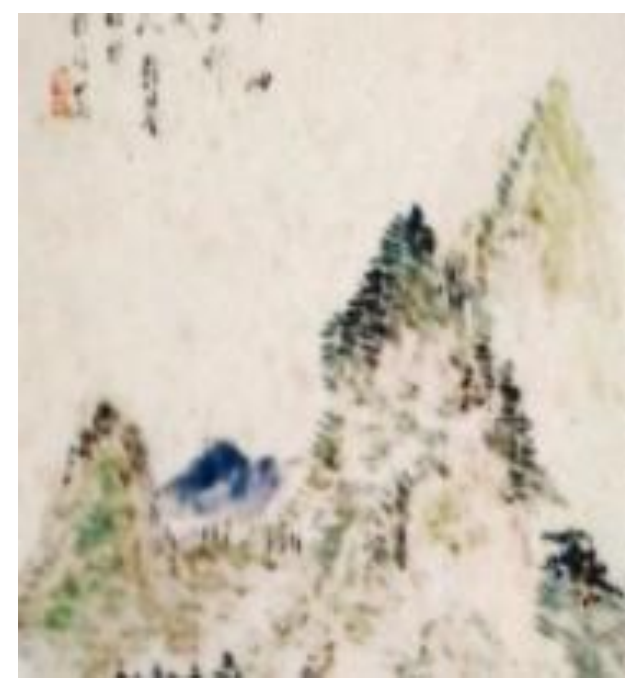

Fig. 6. The partial painted porcelain of "Zhuli Lutun Tu Porcelain Plate" from Cheng Men, the 7th Guangxu year (1881), $40 \mathrm{~cm}$ long, $30 \mathrm{~cm}$ wide. Inscription: Yuanjing Chuangzhongxiu, Guyan Zhulitun.(Watch the far sight from window, the alone wild goose live in the bamboo forest). Appreciated by Mr. Yue Qing in summer of 1881. 


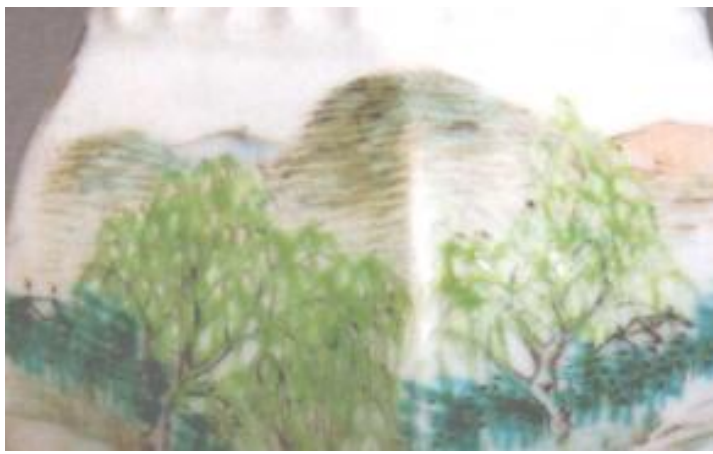

Fig. 7. The partial painted porcelain of "Light crimson colored drum-shaped ewer with flower and bird landscape", the Guangxu Kuimao year (1903), 10 cm high

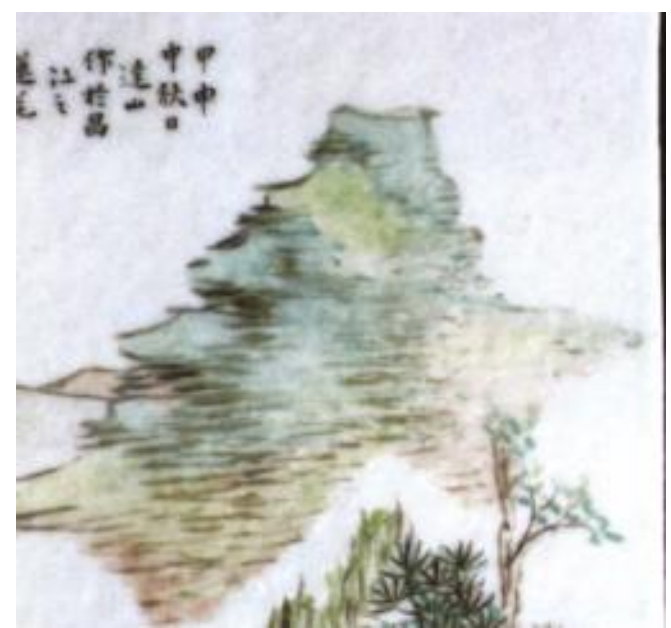

Fig. 8. The partial painted porcelain of "Square Bottle with Flower and Bird Landscape", Wan Ziming, $34.5 \mathrm{~cm}$ high.

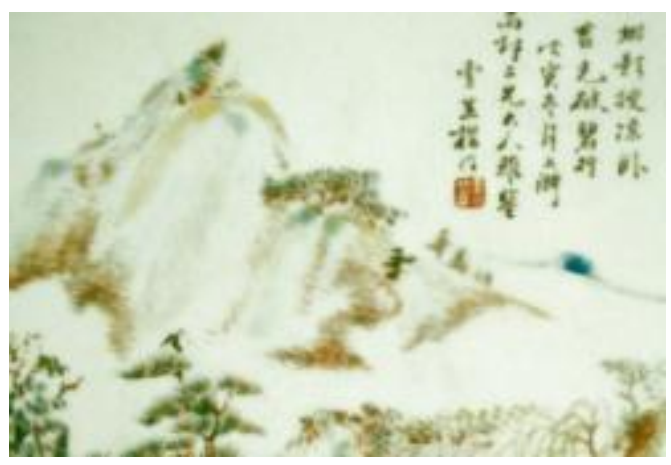

Fig. 9. The partial painted porcelain of "Shuying Souliangtu Porcelain Plate", painted by Cheng Men, the 4th Guangxu year (1878), $20 \mathrm{~cm}$ long and $20 \mathrm{~cm}$ wide. Inscription: Shuying Souliangwo, Taiguang Pobixing.(The tree shadow makes a good cool place to lay down, the moss light walks on the green stone). Appreciated by Brother Han and Yu in Wu Yin winter. Xue Li Cheng men. Stamp: Xue Li

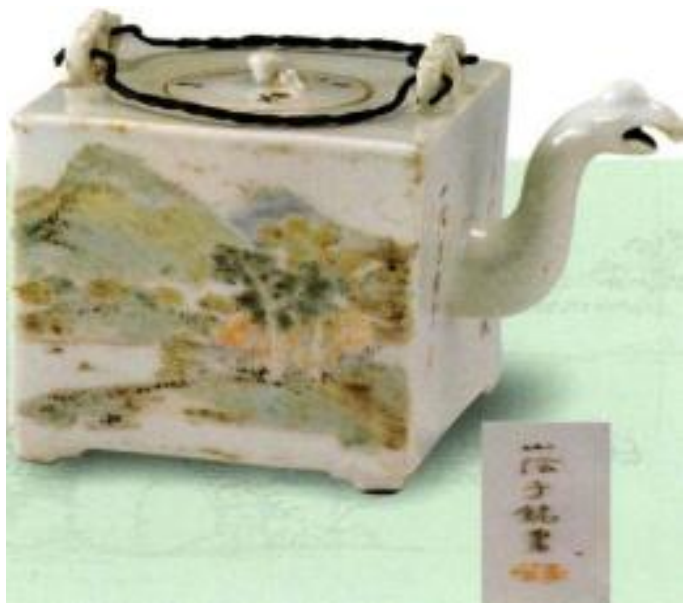

Fig. 10. "Light Crimson Colored Landscape Square Pot With PhoenixHeaded Spout" Zi Ming, style name Shanyin, birth and death date unknown, active in the Qing Guangxu years, good at landscape, flower and bird painting, he was the light crimson colored porcelain artist. Size: mouth $4.5 \mathrm{~cm}$, bottom edge $9.3 \mathrm{~cm}$, through height $11.2 \mathrm{~cm}$. Age: the Guangxu Ren Chen year (1892). Inscription: Yesao Hanying zhulvchen, Songfeng Ruding gengqingxin. Yueyuan Yingluo yinheshui, Yunjiao Xiangrong yushuchun.(At night sweeping the cold snow to boil tea, the tree breeze into the boiler makes the tea more fresh. The round moon shadow fall into the silver river, the cloud melt down the snow on the tree.) Wrote by Shanyin Shuisheng at Wulin Keci in autumn of 1892. Painted by Shanyin Zi Ming. Appreciated by brother Zi Yang.

\section{Light Touch of Shadow-Description of Lightvirtual Spirit}

Another highlight of the light crimson painting is the beauty of light color, porcelain surface is crystal clear, light color and light ink will become illusory, and then produce aesthetic feeling. The representative work is $\mathrm{Hu}$ Dayou's "Yuanshan Yanyutu High Feet Ornamental Plate" ("Fig. 11"), the pen craft and color of each piece of porcelain painting are light and elegant, the image is vague and difficult to distinguish, such like across mist and drizzle. It has both "Shenyuan" ${ }^{11}$ sense of hierarchy, and also with virtual reality illusion, mood is rendering extremely elegant. This kind of works often pay attention to the rendering of artistic conception, evoking people's associations with vaguely shape, which is in line with the "Call structure of art" theory which point out by German accept esthetician Olfug Yisel, art blankness and uncertainty will lead views' creation and supplement and further more to produce deeper artistic resonance. The suggestive material and color in porcelain painting linked to people's real life, and form a unified form language relationship, so to make the painting's color, environment, emotion and shape harmony with each other.

\footnotetext{
${ }^{11}$ Song Dynasty Guo Si gathered his father Guo Xi's "Lin Quan Gao Zhi" proposed "San Yuan method" which has far-reaching impact on Chinese landscape painting, which are: Gaoyuan, Shenyuan, Pingyuan.
} 


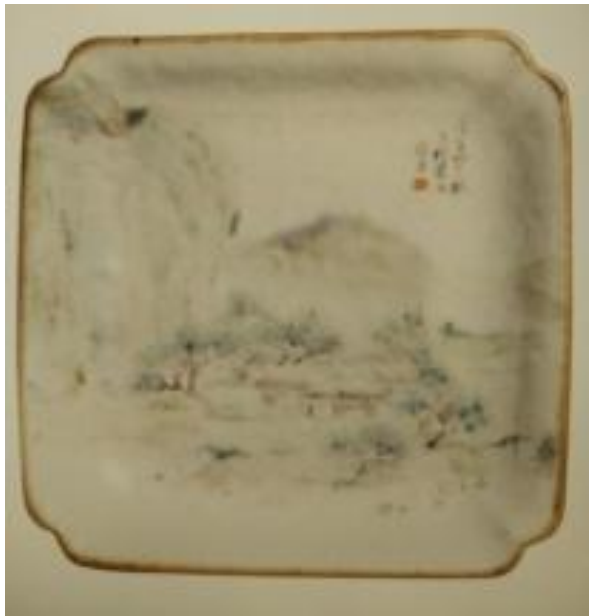

Fig. 11. "Yuanshan Yanyutu High Feet Ornamental Plate" Wu Dayou. $6.5 \mathrm{~cm}$ high, $16 \mathrm{~cm}$ long. Inscription: Jing Sheng made in Lvci.

\section{Planning the Mountain and Forest-Tend to Be Stylized and Decorative}

At the end of Qing Dynasty many porcelain artists originally are painters, they did not have deep skills with literati painting, so many colored landscape porcelain paintings show the tendency of stylization, but some works could obtain a sense of order in the relationship between layout and form, so it has decorative effect. The painting style is actually the product which combined the literati landscape painting theme and the craftsman's long-term experience of drawing decorative patterns, such as the works "Light Crimson Colored Landscape Teaboard" ("Fig. 12"). Another kind of porcelain painter often has a high literati painting accomplishment, they have a certain understanding with art language, they purify and refine the formal relationship between language and layout, so to get decorative aesthetic feeling. Such as: "Tianshan Bishuitu Elephant Handicap Bottle", "Light Crimson Colored Landscape Teaboard" ("Fig. 13"). "Teaboard" small and interpenetrated color plane and flat large color blocks constitute the overall structure of the picture, the high light of hue relationship express the beauty of order and formal rhythm. The beauty of this style mainly comes from the harmonious relationship between proportion and abstract form. Porcelain artist consciously abstract and induce language in traditional landscape paintings, and then to carry on a norm by certain rules, so the formal order has obvious subjectivity. Although these aesthetic results do not meet the literati painting's aesthetic requirements of the "natural" and "freehand", but they do have another different world because they express a certain form of aesthetic feeling.

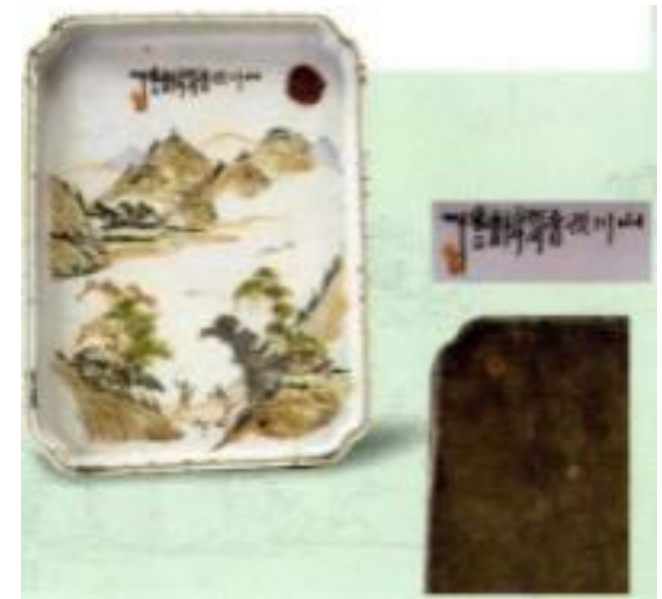

Fig. 12. "Light Crimson Colored Landscape Teaboard" Yunshan, birth and death date unknown, active in Qing Guangxu years, good at landscape, flower and bird painting, he was the light crimson colored porcelain artist. $24.3 \mathrm{~cm}$ long, $17.6 \mathrm{~cm}$ wide, $2.2 \mathrm{~cm}$ high. Age: Guangxu Bingwu year (1906). Inscription: Shanchuan gongxiu. Painted by Yunshan in summer of 1906.

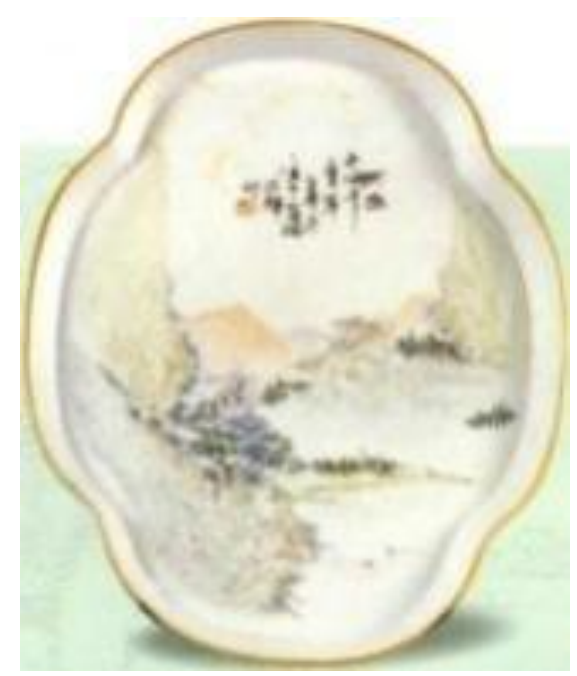

Fig. 13. "Light Crimson Colored Landscape Teaboard", the Qing Guangxu Renwu year (1882). $27 \mathrm{~cm}$ long, $21.3 \mathrm{~cm}$ wide, $2.5 \mathrm{~cm}$ high. Inscription: Shupai Shanmian qianchongcui (Trees lines in front of mountain to make it thousand layers green)Wrote by Ting Hui at Changpu in winter of 1882.Ting Hui, birth and death date unknown, active in the Qing Guangxu years, good at drawing light crimson landscape, he is a light crimson colored porcelain artist.

\section{E. Return to Explore Ink Charm-Pursuing the Tradition}

Since the literati painting into porcelain, the light crimson always followed the creation method of "imitating the ancient, learning from the ancient and changing from the ancient", and moved the ancient pen craft characters, shapes and patters into the porcelain paintings. The paintings of traditional masters are regarded as endless art treasures. The painting method is also cherished by people. Black material as main material, pursuit the ancient people's ink interests, and the screen is often with bleak, lonely feeling. Porcelain paintings take the paper-silk painting effect as the contrast, although the painting material is limited, and lack of vitality and creativity because can not go beyond the paper silk painting, but because of the deep appreciation of the paper painting makes this kind of porcelain 
painting works have refine pen craft, rich ink, complete and balanced composition, with cultural thickness and characteristics. Representative work it Cheng Yan's "Mi's Landscape Porcelain Plate".

\section{F. The Beginning Great Simple-Simple Creation Direction}

Light crimson colored porcelain originally produced in folk, it was shining brightly after the literati and professional painter's transformation. However, there are always some porcelain painting works drawn by the bottom artists to meet the daily needs of general public, gentry and even the farmers, but before these artists have skilled painting technology, their paintings normally with very unadorned and childish expressions. In addition, some officials and literati who prefer light crimson colored porcelain also painted a lot of porcelain painting works, and regard this act as a part of elegance life. As well as the mature artist with good manner freely painted without any rules, these works also belong to this category. Their images often with flawed pencraft, the image is simple and funny, or use strong colors and strong black material to delineate landscape, the screen shows a thick, strong, modesty, simple shaped form features. Representative works are Shao Meizhi's "Light Crimson Colored Landscape Pot Set" ("Fig. 14") and Wang Youtang's "DuMu Shiyitu" (“Fig. 15”).

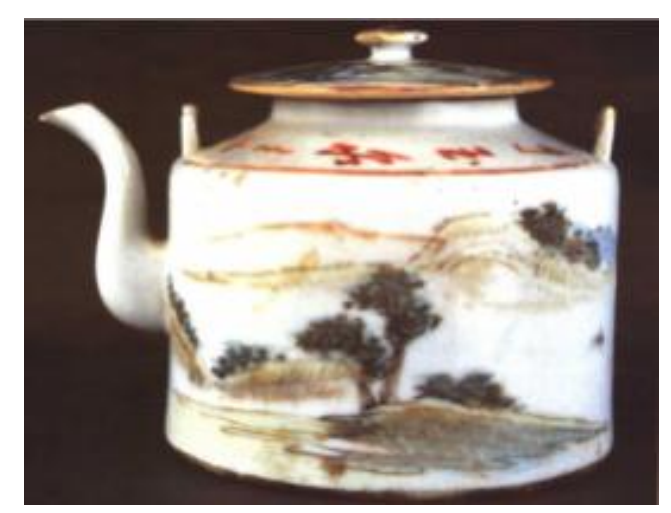

Fig. 14. "Light Crimson Colored Landscape Pot Set" by Shao Meizhi, pot $10.72 \mathrm{~cm}$ high. Inscription:Qingshan Hengbeiguo, Baishui Raodongcheng.( green mountain lies on the north of the village, white river circles the east of the village). Shao Meizhi wrote at Chang Jiang Kexuan in autumn of the Renwu year.

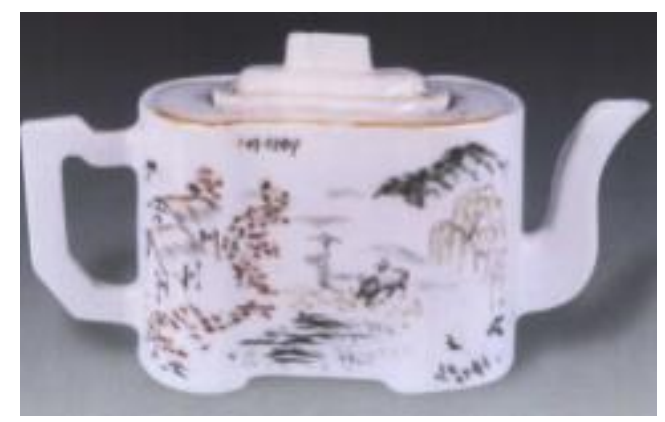

Fig. 15. "DuMu Shiyitu" by Wang Youtang, in the Guangxu Yiwei year. 11 $\mathrm{cm}$ high. Inscription: Xingyanxia zhisumeng biejuxiangzi, Youfeng yuezhigaodan, Bianraoyiqu. Wang Youtang wrote at Changpu in summer of Yiwei year.
The formation of painting style is not entirely depend on the artist's subjective desire, it formed during the continuous communication between the artist and the art materials, which has a general expression in porcelain landscape paintings. Because the difference between paper silk material and porcelain material, so makes the artistic style appeared differences in objective which is difficult to eliminate. Porcelain artists make the best use of the situation and create new language. Such as a lot of colors in literati landscape painting are transparent, so the coloring is mainly cover dyeing; and the color coverage of light crimson painting is strong, so the cover dyeing effect can only be very light, and use different colors directly delineate stone and tree makes the colors interpenetrate with each other, so that between color and color it formed a similar "color mix" effect, not only will form an uncertain inter-color, but also makes the color to maintain a high degree of purity and simple sense of hue. In paper silk landscape painting the paper silk has a moisturizing effect with ink, so it is easy to produce the vivid effect; but for porcelain, its surface is smooth, color attached to the porcelain surface can not produce the moisturizing effect of ink, and it will produce the mechanism effect of pen marks, so porcelain artists use this mechanism effect to strengthen the writing traces, every trace connected with each other formed a consistent feeling. It can be said that the light crimson painting highlights the "Yi Bi Cao Cao" pencraft is actually use the "dynamic and beating short line mechanism" to make the screen consistent. Because of its painting is on the surface, so porcelain painting has ups and downs in picture compare with paper silk painting, which requires painter has full consideration of the relationship between viewing angle changes and the painting structure arrangement, the density relationship also need to change.

\section{CONCLUSION}

In recent years, many researchers have fully affirmed the value and significance of light crimson colored porcelain from different angles. As for the style meaning of light crimson landscape painting, the author thinks that it is the complement of the literati landscape painting from artistic expression forms (only this supplement is in porcelain field). In traditional Chinese landscape paintings, the coloring landscape painting is mainly green landscape, although the achievements are remarkable, but the form is single, often not as impromptu as the literati paintings, but the literati paintings always emphasis ink attainments, the attempt for colors is very limited. So although the light crimson landscape painting is only existed for 60 years, but it uses universal literati's aesthetic tendency as content, use color to interpreted and evolved almost all the styles of landscape painting masters, it was far beyond the limitation of "Light crimson"12[12], and on the basis of the overall process and artistic characteristics evolved simple writing to express nature, planning mountain and forest, gray color with strong emotion, return to explore ink charm, light touch of shadow, the beginning great simple these six art style

\footnotetext{
12 Although the initial light crimson color is black red color, but with the involvement of literati painters, light crimson has been a fundamental change. Its coloring methods and color categories are also beyond the range of "light crimson".
} 
tendencies. It is not only literati painting porcelain, but also a reality combination attempt of color and literati painting. It is not only the cultural extension of literati landscape painting in the porcelain painting, but also in the pattern creation formed under the specific porcelain material limit. It has great referential significance to the development of Chinese landscape painting. Of course, because of light crimson painting always method of "learning from the ancient and the ancient", the painting of the painting in shallow water has always take "learn from the ancient, change from the ancient" as its creative method, so it brought the singularity of artistic subject, artistic pattern can not surpass the fence of literati painting, which makes the painting creation always single and stylized.

As a relatively complete innovation and inheritance to blend in other art forms into porcelain hand-painting, light crimson painting has enlightening significance. In the commercialized today, small to teapots, tea bowl, large to the entire hand-painted porcelain industry are all stressed in the innovation in process and style form. Fast-food style creation rhythm makes the new style complex and redundant, "every porcelain painter must have one or several unique porcelain painting styles, apprentices can not like the teacher "has become a" positive value". When we faced the history of light crimson painting not only emerged a variety of style tendencies, but also unified into one style system, it is not difficult to find that in today's over emphasis on the diversity and individuality of art forms, we seem to play down the important role of a relative stable art form style. "Relative stability" will make a clear link between the style differences, and constitute cultural system in local part. It can gather more talented artists and form the collective advantage, through time and space, so that the porcelain hand-painted level continues to increase, deepen and expand, and enhance its social and cultural influence.

When the diversity of art has been deeply rooted in the people, perhaps it's time we come back to thinking about how to make these existing "form results" deeply developed between the generations in order to avoid they become a flash in the pan.

\section{REFERENCES}

[1] Zhou Jiyin,Discussion on Chinese Painting. Jiangsu Fine Arts Publishing Company, 1985.

[2] Jiang Siqing, History of Jingdezhen Cramics. Jingdezhen Ceramic Institute, 1956.

[3] Liang Jiyong, China Light Crimson Painted Porcelain. Beijing: Cultural Relics Press, 2000.

[4] Liang Jiyong, Appreciation of China's Light Crimson Painted Porcelain Painting, Hangzhou: Zhejiang Photographic Publishing Company, 2004.06.

[5] HeJinxing, Light Crimson Painted Porcelain Pot Master Works Appreciation.Pot Collection Notes. Yunnan Fine Arts Publishing Company, 2008.07.

[6] Chen Jianxin, Mu Qing, Liu Zhengbo. Light Crimson Painted Porcelain Painting. Hebei People's Publishing Company 2003.03.

[7] Hu Yuejun, Chen Shuqun. Hundred Masters of Light Crimson Paintings. Hangzhou: China Academy of Fine Arts Press, 2008.
[8] Yu Jiming. Master Paintings of Light Crimson Painted Porcelain Paintings. Zhejiang University Press, 2005.04.

[9] Zi Wuyuan. Literiti Paintings on Porcelain.Light Crimson Painted Porcelain in Late Qing Dynasty and Republic of China. Hangzhou: Zhejiang University Press, 2006.01.

[10] Xu Jinfan, Chen Bing. China's Late Qing Dynasty Light Crimson Porcelain. Shanghai: Shanghai People's Fine Arts Publishing Company, 2011.

[11] Bai Wenhong, Masters' Light Crimsonpainted Porcelain. Shenyang: Million Rolls Publishing Company, 2005.

[12] Zhi Kuang. The Late Qing Dynasty Folk Light Crimsonpainted Porcelain Appreciation. Hangzhou: Hangzhou Press, 2004.

[13] Yu Qiancheng. Chinese Folk Shallow Purple Color Porcelain Illustrations. Zhejiang Photographic Publishing House, 2002.11.

[14] Yu Jiming. I Said Late Qing Dynasty Light Crimson Painting. Zhejiang University Press, 2007.06.

[15] Liu Changbin. Master Thesis: The Art Style of Light Crimson Porcelain Paintings. Nanjing Art Institute, Fine Ar ts, 2003. 